\section{Portal vein filling: an unusual complication of needle-knife sphincterotomy}

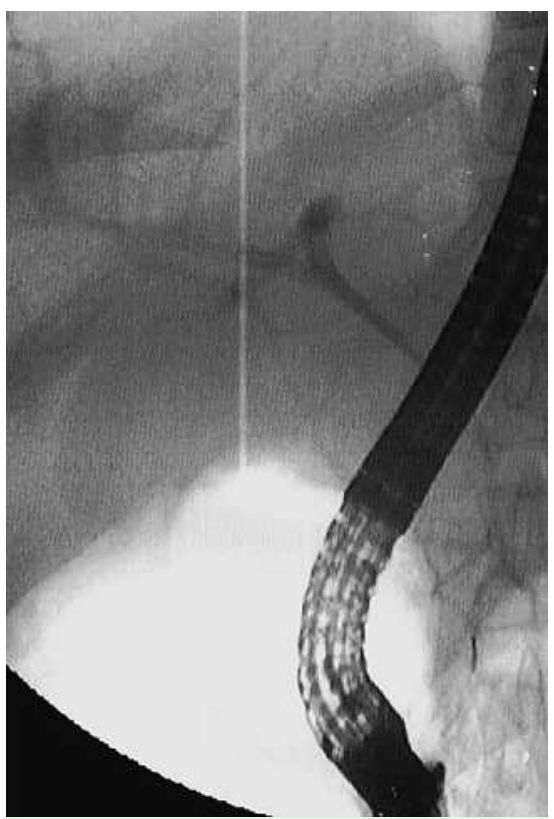

Fig. 1 Endoscopic retrograde cholangiopancreatographic view showing communication with and opacification of portal veins after needle-knife sphincterotomy.

The most frequent complications associated with endoscopic retrograde cholangiopancreatography (ERCP) are pancreatitis, hemorrhage, and perforation. We report an unusual case of portal vein filling after needle-knife sphincterotomy in a patient with a pancreatic carcinoma. A 59-year-old woman was admitted to our hospital with obstructive jaundice, fever, elevated liver enzymes, and dilatation of the biliary and pancreatic ducts. Magnetic resonance imaging revealed a mass at the head of the pancreas. An ERCP with needle-knife sphincterotomy was performed over a pancreatic stent after several failed cannulation attempts.
On cannulation, contrast was noted to clear within a few seconds ( Figure $\mathbf{1}$ ). Aspiration revealed blood, indicating possible cannulation of the portal vein, and the procedure was terminated immediately. The patient went into atrial fibrillation in the recovery room, but this reversed spontaneously within 6 hours.

The patient was operated on 3 weeks later. She was found to have an adenocarcinoma of the pancreas with no signs of portal vein infiltration, and a cephalic duodenopancreatectomy was performed. Histological examination of the resected specimen identified an infiltrating ductal adenocarcinoma, stage T3NOM0, with infiltration of the superior mesenteric vein. The patient subsequently received chemotherapy and radiation therapy and has remained stable over the 6 months since her operation.

Filling of the portal venous system is an infrequent complication of ERCP, with an incidence between 1 in 6000 and 1 in 8000 cases [1,2]. Most of these patients presented with adenocarcinoma of the pancreas. It has also been described with different cannulation techniques $[3,4]$. This complication can result from laceration of a small portal vein [2-4] or from direct trauma to the papilla [5]. Neo-angiogenesis or aberrant vessels resulting from the cancer can also explain its occurrence, as reported in the literature.

Filling of the portal vein at ERCP carries potential risks, including bleeding, sepsis, thrombosis, and air embolism. Aspiration of the duct before the injection of contrast might aid in its prompt diagnosis.

Endoscopy_UCTN_Code_CPL_1AK_2AC
J. Espinel ${ }^{1}$, M. E. Pinedo ${ }^{2}$, J. L. Calleja ${ }^{3}$

${ }^{1}$ Digestive Apparatus Service, Hospital de Leon, Leon, Spain

2 Radiodiagnostic Service, Hospital de Leon, Leon, Spain

${ }^{3}$ Department of Gastroenterology and Hepatology, Hospital Universitario Puerta de Hierro, Madrid, Spain

\section{References}

1 Ricci E, Mortilla MG, Conigliaro R et al. Portal vein filling: a rare complication associated with ERCP for endoscopic biliary stent placement. Gastrointest Endosc 1992; 38: 524-525

2 Siegel JH, Ben-Zvi JS, Yatto RP. Portal vein filling during ERCP. Gastrointest Endosc 1993; 39: $471-472$

3 Huibregtse K, Gish R, Tytgat GN. A frightening event during endoscopic papillotomy. Gastrointest Endosc 1988; 34: 67-68

4 Lum C, Cho KC, Scholl DG et al. Portal vein opacification during ERCP in patients with pancreatitis. Abdom Imaging 1998; 23: $81-83$

5 Ben-Zvi JS, Siegel JH, Yatto R. Opacification of the portal system during ERCP: demonstration of an anomalous pancreatico-portal connection in a patient with pancreatic carcinoma. Gastrointest Endosc 1989; 35: $445-447$

Bibliography

DOI $10.1055 / s-2007-966156$

Endoscopy 2007; 39: 245

(c) Georg Thieme Verlag KG Stuttgart · New York . ISSN 0013-726X

\section{Corresponding author}

\section{J. L. Calleja, MD}

Department of Gastroenterology and Hepatology Hospital Universitario Puerta de Hierro

CP 28035 Madrid

Spain

Fax: +34-91-3730535

jlcpan@terra.es 